\title{
Good bugs gone bad: Coccinellidae, sustainability and wine
}

\author{
G. J. Pickering ${ }^{1}$, E. J. Glemser ${ }^{2}$, R. Hallett ${ }^{2}$, D. Inglis ${ }^{1}$, \\ W. McFadden-Smith ${ }^{1,3}$ \& K. Ker ${ }^{1,4}$ \\ ${ }^{1}$ Brock University, Canada \\ ${ }^{2}$ University of Guelph, Canada \\ ${ }^{3}$ Ontario Ministry of Agriculture, Food \& Rural Affairs, Canada \\ ${ }^{4}$ KCMS Applied Research and Consulting Inc., Canada
}

\begin{abstract}
Coccinellidae ('ladybeetles') are generally known as beneficial insects. Many are voracious predators feeding upon harmful pests such as aphids, scale insects, mealy bugs and mites. Coccinellidae species have been introduced into many regions around the world as bio-control agents for a range of grains, fruit and other crops. However, in part because of a northerly migration due to global warming, introduced species are now displacing native Coccinellidae species in some areas, and reaching densities that pose significant challenges for the grape and wine industries. Harmonia axyridis and Coccinella septempunctata are increasingly found in vineyards, and when they are inadvertently incorporated with grapes at harvest they produce a very potent odorant that taints the subsequent wine ('ladybug taint'). This has significantly devalued grapes and wine from many regions over the last decade, and the beetles responsible now represent one of the greatest threats to the industry. Approaches for dealing with this novel pest have focused on repellency or exclusion of the beetle from the fruit or vineyard, and on remediation of juice and wine affected by ladybug taint. To date, the use of insecticidal sprays in the vineyard - including the synthetic pyrethroid, cypermethrin, and the organophosphate, malathion - has been the treatment of choice, but their use raises issues related to residues, phytotoxicity and wine quality. We present data from our labs on two alternative options. The first involves the use of potassium metabisulphite - commonly used in wine as an antimicrobial and antioxidant. Y-tube olfactometry and field studies show significant repellency effects (up to 50\%) on Coccinellidae. In the second study, a range of grape-derived non-toxic compounds were assessed for their potential
\end{abstract}


efficacy as part of an integrated and sustainable 'push-pull' strategy for dealing with this invasive pest.

Keywords: Coccinellidae, invasive species, ladybug taint, pesticide, sustainability, adaptation, grape, wine.

\section{Introduction}

Various species of Coccinellidae (popularly known as 'lady-birds', 'lady-bugs', or 'lady-beetles') have been introduced into many regions around the world, including the USA, Europe and South America, as bio-control agents for grains, soybeans, conifers, ornamentals, fruit and other crops. This is particularly true of the Multicoloured Asian Ladybeetle Harmonia axyridis (Pallas) (Coleoptera: Coccinellidae), which was first introduced to North America in 1916 from Asia, and on multiple occasions since, to control aphids and some small soft-bodied pests Koch et al. [1]. In part due to global warming, these beetles have been able to migrate, survive and proliferate in once climatically unsuitable regions, including much of the north-eastern USA and southern Ontario, in Canada. In so doing, they have successfully out-competed native Coccinellidae species, affecting the ecological balance of many systems. One unforeseen consequence of the proliferation of $H$. axyridis has been their negative impact on grape and wine quality.

$H$. axyridis enter vineyards in autumn, possibly to consume grape carbohydrates in preparation for overwintering, and are often found at high densities within individual grape clusters, fig. 1.
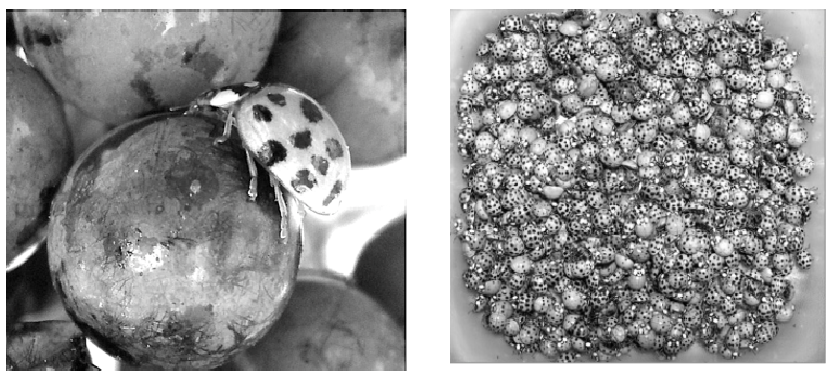

Figure 1: $\quad$ The Multicoloured Asian Ladybeetle (Harmonia axyridis (Pallas)) (photo courtesy of Kevin Ker and Ryan Brewster).

When the grapes are harvested, many beetles are also inadvertently collected, and following crushing and pressing operations in the winery, impart the resulting juice and wine with an unpleasant aroma and flavour coined 'ladybug taint'. The affected wines are characterised by undesirable peanut and bellpepper aroma and increased bitterness Pickering et al. [2]; the aromatic component of the taint due to alkyl-methoxypyrazines released from the haemolymph of the beetles Pickering et al. [3]. Recently, a second Coccinellidae 
- Coccinella septempunctata - has also been shown capable of eliciting ladybug taint in wine Botezatu and Pickering [4].

Traditional winery interventions and treatments have proven largely ineffective in remediating this taint Pickering et al. [5], leading to increased efforts to exclude the beetles from the vineyard or from entering the wine production cycle. Currently, this is achieved through insecticide applications in the vineyard, and to a lesser extent, the use of 'shaker trays', which remove beetles from harvested grapes prior to further winery operations. In the USA, these insecticides include Clutch $^{\circledR}$ 50WDG (clothianidin), Venom ${ }^{\circledR}$ 70SG (dinotefuran) and Mustang ${ }^{\circledR}$ Max EC (permethrin) with pre-harvest intervals ranging from 0-1 days. In Canada, grape producers use Malathion $85 \mathrm{E}$ (malathion) and/or Ripcord ${ }^{\mathrm{TM}} 400$ EC (cypermethrin) up to 3 and 7 days prior to harvest, respectively OMAFRA [6]. One of the challenges of these insecticides is that re-infestation may occur rapidly, as beetles are highly mobile and their densities in vineyards can fluctuate greatly from day to day Seko et al. [7]. In an attempt to remove beetles from grapes immediately prior to harvest, injudicious use of insecticides may occur, increasing the risk of unsafe levels of pesticide residues Ker and Pickering [8]. Thus, alternative, safe and sustainable strategies for controlling $H$. axyridis in vineyards are necessary, consistent with the wider movement toward reduced-risk pest management practices in agriculture.

A semiochemical-based push-pull strategy is consistent with this goal. Under such an approach, both highly attractive and highly repellent stimuli are used to manipulate the abundance and distribution of the beetles in the vineyard. They are repelled (pushed) from the areas in need of protection and simultaneously pulled towards a trap or non-protected area Miller and Cowles [9]. The push-pull strategy utilizes stimuli that are generally non-toxic, such as semiochemicals Cook et al. [10]. Some clues as to which chemicals may be effective in this regard come from observation of Coccinellidae behaviour in the vineyard. $H$. axyridis have been observed feeding on table grapes, but generally do not feed on fruit with intact skins Koch et al. [1]; Galvan et al. [11]. The presence of $H$. axyridis in grape clusters is also strongly correlated with the presence of damaged or over-ripened fruit Galvan et al. [12], raising the possibility that fermentation products associated with ripe or damaged grapes may be acting as attractants. Fermentation products of aphid honeydew have previously been shown to be olfactory attractants of $H$. axyridis, aiding them in locating aphid prey Bahlai et al. [13].

One potentially repellent chemical to Coccinellidae that has not previously been assessed is sulphur dioxide; a commonly used antimicrobial and antioxidant used throughout the food and wine industries. Sulphur dioxide is typically added to food and beverages in the form of potassium metabisulphite (KMS), which produces sulphur dioxide upon hydrolysis. In wine, it prevents browning and inhibits the activity of many spoilage bacteria and yeast Ough and Were [14]. While KMS is not yet registered for use in vineyards, it is permitted in winemaking in all wine regions and is relatively inexpensive; thus its use in vineyards may be more appropriate than many other chemicals for repelling beetles. 
In two separate studies presented here, we sought to evaluate the effectiveness of KMS as a repellent against $H$. axyridis, and to assess a range of grape-derived compounds for their potential use in a push-pull strategy for managing H. axyridis in the vineyard.

\section{Materials and methods}

\subsection{Study 1: KMS}

\subsubsection{Olfactory assays}

A glass Y-tube olfactometer was used to evaluate the response of adult $H$. axyridis to KMS. Three concentrations of KMS (ABC Cork Co., London, ON) were tested in bioassays: $2.5,5$, and $10 \mathrm{~g} / \mathrm{L}$, corresponding to $1 / 2,1$ and 2 times the experimental rate used by Balasubramaniam and Poole [15], respectively. Compressed, charcoal-filtered air was split into two airstreams and the flow rate of each airstream was adjusted with a flow meter (Key Instruments, Trevose, PA) to $200 \mathrm{~mL} / \mathrm{min}$. Optimal flow rate within the olfactometer was determined using smoke as described by Vet et al. [16]. Each airstream passed through a 50$\mathrm{mL}$ Büchner flask, containing either $10 \mathrm{~mL}$ of distilled water or KMS at one of the three concentrations, before entering the olfactory arena. Control and treatment arms were alternated after every five repetitions. Before each beetle was tested, the Y-tube and Büchner flasks were cleaned with hexane, soap and water, and then oven dried at $\geq 100^{\circ} \mathrm{C}$. Olfactory assays were conducted using laboratory-reared beetles. Adults were sexed using external morphological characteristics as described by McCornack et al. [17]. Beetles were selected at random from cages and individuals were tested once per treatment. Olfactory assays were conducted with adults less than three weeks old. Ten males and 10 females $(N=20)$ were assayed. Individual beetles were gently placed into the end of the Y-tube, which was then covered with nylon mesh to prevent beetles from escaping. Beetle movements were then recorded for $10 \mathrm{~min}$. Beetles that did not move from the base of the olfactometer into one of the arms were considered non-responders and were excluded from analyses. Each assay was conducted until results with 10 responsive beetles of each sex were obtained. The total time spent in the treatment and control arms was expressed as a proportion of the observation period (600 s). If any proportion equalled 0 (i.e. beetles spent no time in one arm), then the value was replaced with $1 /(4 n)$ where $n$ is $600 \mathrm{~s}$ to avoid 0 values Bartlett [18]. Proportions were arcsine square-root transformed to improve normality Sokal and Rohlf [19], and analysis of variance (ANOVA) was used to test for the effect of KMS on the proportion of time beetles spent in treatment and control odour fields. Tukey's multiple comparisons test, with $\alpha=$ 0.05 , was used to separate significant effects. Fisher's exact binomial test was used to determine if the observed frequency of beetle location in treatment areas deviated significantly from random after 1 and 10 minutes of assay, where the expected frequency for both KMS and control arms was $p=0.50$. 


\subsubsection{Vineyard trial}

A field experiment was conducted to evaluate repellency of KMS in a 2.3 ha wine grape (Vitis vinifera var. Gewürztraminer) vineyard located below the Niagara escarpment in Beamsville, ON. The experiment was located on the south side of the vineyard between the second and third posts to avoid potential edge effects. Treatment plots consisted of a $7 \mathrm{~m}$ row length (i.e. post to post) and included 5-6 vines. Treatments were arranged in a randomized complete block design and in each experiment treatments were replicated five times. After a preliminary trial earlier in the season, two KMS treatments were applied at 5 and $10 \mathrm{~g} / \mathrm{L}$ on 29 October 2009. Control vines were sprayed with water alone. KMS treatments and water alone were applied as foliar sprays using a carbon dioxidepressurized precision plot sprayer at $350 \mathrm{kPa}$ in water equivalent to $1000 \mathrm{~L} / \mathrm{ha}$. A four-nozzle boom spray was used which allowed for uniform coverage of the entire vine. Plots were sprayed on both sides and were separated by a one-row buffer. Observations on the presence of $H$. axyridis were made $24 \mathrm{~h}$ after application. Five vines from each plot were examined. For reliability of data collection, two field technicians examined the vines for presence of $H$. axyridis. The technicians worked in tandem looking at the same vine, one on either side. This system increased accuracy and efficiency by limiting the potential for double counting or overlooking beetles. The number of $H$. axyridis present on vines was subjected to an ANOVA (PROC MIXED; FIXED rate; RANDOM block). Tukey's multiple comparisons test, with $\alpha=0.05$, was used to separate significant effects.

\subsection{Study 2: Grape-derived volatiles}

\subsubsection{Selection of relevant compounds and preparation of grape juice}

Grape clusters (cv Riesling and Pinot noir) were collected from Vineland, Ontario, in October at peak maturity. Selected clusters were classified by damage severity (clean, compromised or severely damaged) and were analysed for acetic acid, acetaldehyde, ethanol and ethyl acetate content. Standards and chemicals were purchased from Sigma Aldrich (Oakville, Canada). Acetic acid, acetaldehyde and ethanol were measured using enzyme kits from Megazyme (Wicklow, Ireland), according to the manufacturer's instructions. Quantification of ethyl acetate was carried out using an Agilent 6890 Gas Chromatograph (CA, USA) with a flame ionization detector and equipped with a Durabond DB-wax column ( $30 \mathrm{~m} \times 0.25 \mathrm{~mm}$ i.d., $0.25 \mu \mathrm{m}$ film thickness) after the method of Nurgel et al. [20]. The observed values (data not shown) were then used to determine spiking concentrations for subsequent juice treatments. Pettersson et al. [21] reported the role of isopropyl-, isobutyl-, and secbutyl-methoxypyrazines (IPMP, IBMP, SBMP) in attracting the ladybeetle Coccinella septempunctata, so these compounds were also included in the study at a concentration of $10 \mathrm{ng} / \mathrm{L}$ in treatment juices. It has been suggested that IPMP may act as a sex or aggregation pheromone for $H$. axyridis, so an additional lower concentration treatment $(0.1 \mathrm{ng} / \mathrm{L})$ for this compound was included in the study.

Two bushels of grapes (cv Riesling) were harvested by hand from Huebel Farm, Virgil, Ontario. Clusters were sorted to remove rot and damaged berries 
prior to pressing. On the day of testing, thawed juice $(395 \mathrm{~mL})$ was 'spiked' with stock solution of chemicals $(5 \mathrm{~mL})$ prepared in distilled water to reach final concentrations that approximated those found in compromised grapes. After spiking, the concentrations of ethanol, acetaldehyde, acetic acid and ethyl acetate in control and spiked juice treatments were re-measured as described above.

\subsubsection{Insects and olfactometry}

Adult $H$. axyridis were collected daily from vineyards across the Niagara Peninsula grape-growing region during October 2007. Beetles were maintained in mesh cages and provided with moistened paper towel and a supply of washed and sliced Cabernet franc grapes. A random allotment of $50 \mathrm{H}$. axyridis were removed from the holding cages and placed in plastic Ziploc ${ }^{\circledR}$ containers and starved for $24 \mathrm{~h}$ prior to experimentation. No beetle was used more than once per treatment.

A two choice assay was used to evaluate the response of individual $H$. axyridis to olfactory cues commonly associated with ripe and over-ripe wine grapes using the Y-tube olfactometer described above. After preliminary testing, grape juice was selected as the control treatment for subsequent experiments. The control juice sample consisted of $79 \mathrm{~mL}$ of grape juice and $1 \mathrm{~mL}$ of distilled water. The treatment sample consisted of $80 \mathrm{~mL}$ of grape juice spiked with the various compounds of interest. The compounds examined were: acetic acid, $0.5 \mathrm{~g} / \mathrm{L}$; acetic acid, $1.2 \mathrm{~g} / \mathrm{L}$; ethanol, $0.10 \% \mathrm{v} / \mathrm{v}$; ethanol, $0.25 \% \mathrm{v} / \mathrm{v}$; acetaldehyde, $15 \mathrm{mg} / \mathrm{L}$; acetaldehyde, $25 \mathrm{mg} / \mathrm{L}$; ethyl acetate, $100 \mathrm{mg} / \mathrm{L}$; acetic acid, $0.5 \mathrm{~g} / \mathrm{L}+$ acetaldehyde, $15 \mathrm{mg} / \mathrm{L}+$ ethanol, $0.10 \% \mathrm{v} / \mathrm{v} ;$ acetic acid, $0.5 \mathrm{~g} / \mathrm{L}+$ acetaldehyde, $15 \mathrm{mg} / \mathrm{L}$; acetic acid, $0.5 \mathrm{~g} / \mathrm{L}+$ ethanol, $0.10 \% \mathrm{v} / \mathrm{v}$; acetaldehyde, $15 \mathrm{mg} / \mathrm{L}+$ ethanol, $0.10 \% \mathrm{v} / \mathrm{v}$. Each treatment was replicated four times with ten beetles per replicate. Both the treatment and control samples were replaced with new samples after each replicate.

\subsubsection{Statistical analyses}

For each treatment pair, a likelihood ratio (LR) was determined. LR (adapted from Taper and Lele [22]) ranks the likelihood of $H_{o}$ over $H_{l}$, given data $X$. Unlike p-values, LRs also provide a means of comparing strength of response between trials. For our data, $P_{o}=0.5$ as $H_{o}$ is the random response, $P_{I}=0.675$ as $H_{l}$ is the minimum statistically significant response, and $n=40$ trials. LRs were calculated for all possible outcomes and it was determined that preference was favoured by LR when $\geq 24$ of the 40 beetles chose one treatment over the other (60\% choice or greater). Full details of these methods can be found in Glemser et al. [24].

\section{Results}

\subsection{Study 1: KMS}

\subsubsection{Olfactometry}

Fig. 2 shows the proportion of time spent by $H$. axyridis beetles in potassium metabisulphite (KMS) $(\mathrm{g} / \mathrm{L})$ or control arms of a Y-tube olfactometer. Neither 
sex nor the sex*treatment interactions were significant sources of variation; therefore, sexes were pooled for statistical analyses. Beetles were significantly repelled by KMS at all concentrations as they spent significantly more time in control than in KMS arms. Numerically fewer beetles were found in the KMS odour field than in the control odour field at both 1 and $10 \mathrm{mins}$, and this effect was generally more pronounced with increasing concentration of KMS (data not shown).

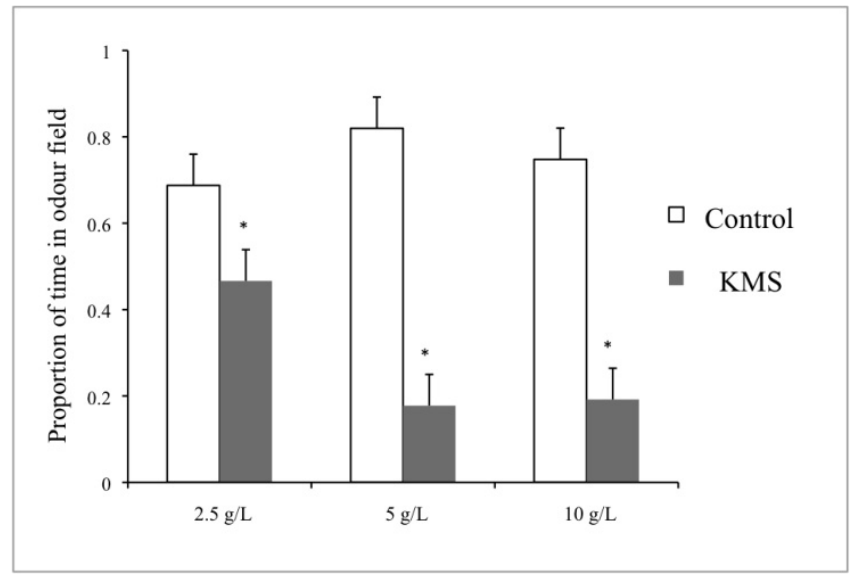

Figure 2: $\quad$ Proportion of time (arcsine square-root transformed; mean $\pm \mathrm{SE}$ ) spent by Harmonia axyridis adults in potassium metabisulphite (KMS) $(\mathrm{g} / \mathrm{L})$ or control arms of a Y-tube olfactometer. For each experiment, $N=20$. Significant differences between treatments and the control are denoted by an asterisk (*) (Tukey's HSD, $\alpha=0.05$ ). Adapted from Glemser et al. [23].

\subsubsection{Vineyard trial}

Harmonia axyridis accounted for all coccinellids observed on grape vines. The number of beetles on vines was significantly reduced by the application of KMS at both levels, fig. 3. Importantly with respect to possible negative impact on the resulting juice and wine quality, the concentration of free sulphur dioxide measured in control juice was not significantly different than that in juices made from KMS-sprayed grapes (data not shown).

\subsection{Study 2: Grape-derived volatiles}

In results reported elsewhere, [24], we unexpectedly found that $H$. axyridis preferred undamaged grapes to damaged grapes, but did not discern between undamaged grapes and blank air nor damaged grapes and blank air. We also found that ethanol, acetaldehyde and acetic acid all increased with increasing degree of damage to grapes. Ethyl acetate concentration of all samples was below the limit of detection. In the olfactometry trials on juice and juice volatiles presented here, preference was observed in 8 of the 17 treatment pairs tested, fig. 4. $H$. axyridis were attracted to acetic acid (both concentrations); 


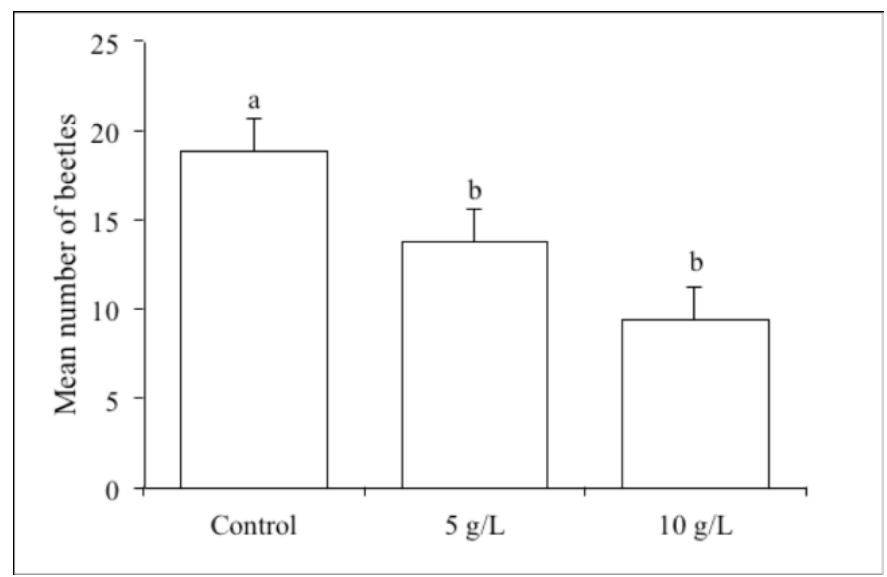

Figure 3: $\quad$ Mean number of Harmonia axyridis present on grape vines (Vitis vinifera var. Gewürztraminer) $24 \mathrm{~h}$ after application of potassium metabisulphite (at 5 , or $10 \mathrm{~g} / \mathrm{L}$ ). Treatments were replicated five times $(N=20)$. Means followed by the same letter are not significantly different (Tukey's HSD; $\alpha=0.05$ ). Adapted from Glemser et al. [23].

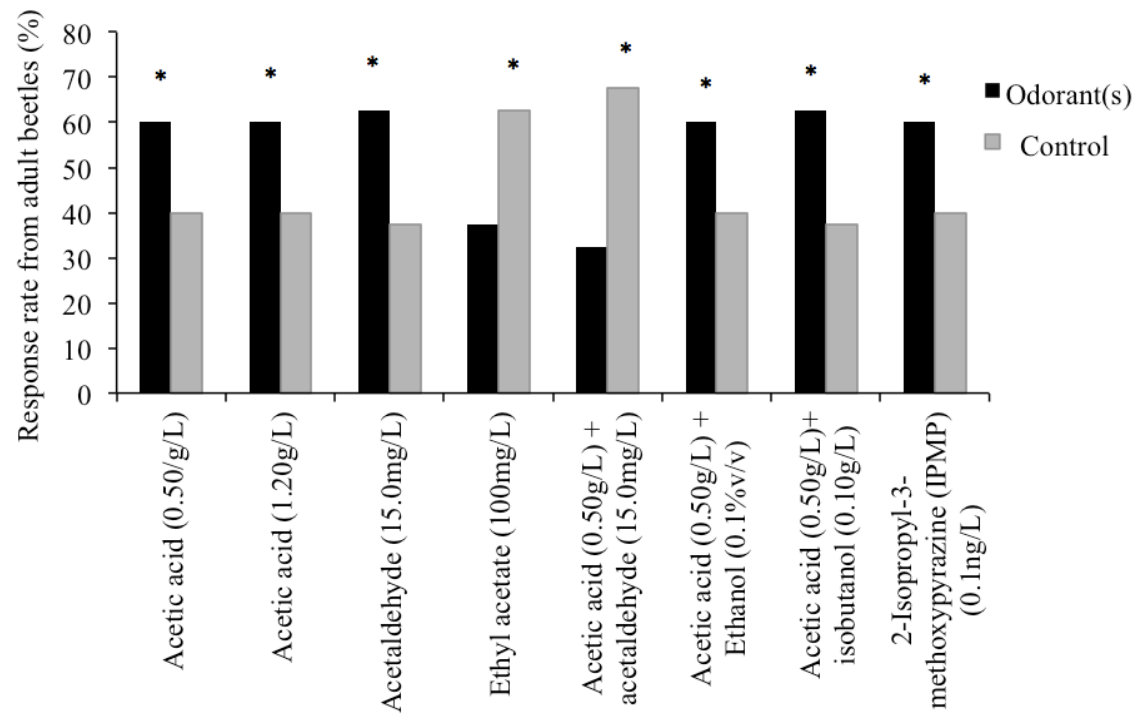

Figure 4: Response of adult $H$. axyridis to volatiles commonly associated with mature grapes. Controls consisted of $79 \mathrm{~mL}$ of grape juice + $1 \mathrm{~mL}$ of distilled water. Treatments consisted of $80 \mathrm{~mL}$ of grape juice + odorant(s) of interest. Only treatments where responses were significantly different from control are shown (likelihood ratio). 
acetaldehyde (low concentration); acetic acid plus ethanol; acetic acid plus isobutanol; and IPMP (low concentration). H. axyridis were repelled by ethyl acetate alone, and by acetic acid plus acetaldehyde.

\section{Discussion}

In laboratory assays, repellency can be attributed to the presence of volatile sulphur dioxide, as beetles did not make physical contact with the KMS solution, while repellency in the vineyard may occur from both volatile sulphur dioxide and physical contact with the mildly acidic KMS solution. Higher numbers of non-responding beetles were seen with increasing concentrations of KMS, suggesting that lack of movement of these beetles may have been due to effects of KMS. The repellency of KMS in vineyards may be affected by environmental is to be used in vineyards, it be applied on calm days. The application of KMS did not eliminate all $H$. axyridis on grape vines, but that may not be necessary; reducing densities to below 1530 and 1260 beetles/t for white and red grapes, respectively, may be sufficient to prevent development of taint in the wines Pickering et al. [25]. If the number of beetles in a vineyard exceeds this established sensory detection threshold, KMS could be used to reduce the number of beetles below the threshold level. KMS applied in the vineyard before harvest did not affect the amount of free sulphur dioxide in either freshly processed or settled juice, and thus no negative effect on the resulting juice and wine quality is expected. In vineyards, the presence of beetles is only a problemduring grape harvest. Attempting to repel beetles from vineyards at any other times is futile as beetles would likely return. Thus, a candidate repellent should be applied immediately prior to harvest without the risk that residues will compromise wine quality. KMS appears suitable in this regard. Additionally, sulphur dioxide is not considered highly phytotoxic Balasubramaniam and Poole [15] and there was no visual evidence that KMS caused phytotoxicity to grape vines in this study. However, a potential issue with the use of KMS in vineyards is environmental pollution, as sulphur dioxide is oxidized and produces sulphate, a major air pollutant and contributor to acid rain Penkett et al. [26].

Our finding that the odour of undamaged grapes was consistently more attractive than that of damaged grapes, and that damaged grapes were observed to be repellent to $H$. axyridis on some occasions, was unexpected. Galvan et al. [12] found a strong correlation between $H$. axyridis and freshly damaged grapes in the field, suggesting that beetles are attracted to damaged grapes, possibly because of their higher sugar content. $H$. axyridis are unable to cause primary damage to grapes [1] and therefore, must find previously damaged grapes for feeding. As a result, the distribution of damaged grapes has been shown to determine the distribution of $H$. axyridis in vineyards Galvan et al. [27]. However, if sugar content alone dictated feeding preferences, we may have expected to see damaged grapes preferred over undamaged grapes in the olfactometry study.

Single compounds and some mixes of volatile compounds associated with spoiled grapes or fermentative metabolites were found to be attractive (acetic 
acid, acetaldehyde, acetic acid plus ethanol, and acetic acid plus isobutanol). Previous studies have shown that specific blends of compounds are often required to elicit behavioural responses in insects Smilanick et al. [28]; Phelan and Lin [29]. While a blend of acetic acid and acetaldehyde repelled $H$. axyridis, the mix of acetic acid, acetaldehyde and ethanol had no effect, indicating that ethanol may dampen the sensory perception of $H$. axyridis, and thereby inhibit avoidance behaviour. Ethyl acetate had a repellent effect on the beetles, although the spiked amount exceeded the detectable level in all of the grape samples. The combination of acetaldehyde and acetic acid in a 1:33 ratio was significantly repellent, and supports the whole grape bioassay result from Glemser et al. [24]. A ratio of 1:30 or higher may be indicative of excessive microbial contamination of grapes; if grapes are too badly degraded, they may not be suitable food for ladybeetles, and are thus unattractive to $H$. axyridis. Many studies have shown that microorganisms mediate insect-plant interactions Domek and Johnson [30]; Hammons et al. [31, 32]. IPMP was the only methoxypyrazine that elicited a behavioural response in $H$. axyridis. IPMP has been demonstrated to be attractive to both sexes of $C$. septempunctata in olfactory bioassays Al Abassi et al. [33]. It is possible that IPMP functions at low concentrations as an aggregation pheromone for $H$. axyridis, whereas higher concentrations may signal high levels of competition.

\section{Conclusion and further research}

The discovery that KMS is an effective repellent against $H$. axyridis suggests that it is a promising control method for use in vineyards, but more research is needed to develop comprehensive pest management recommendations. Future studies should determine the duration of repellency and the effect of environmental conditions, such as wind speed and temperature, on the efficacy of KMS. The behaviour of beetles following KMS applications should also be investigated to determine optimal use patterns of KMS in vineyards, and methods for minimising the release of sulphate (an environmental pollutant) after KMS application are needed. H. axyridis are attracted to ripe grapes, and some chemicals associated with grape spoilage. Olfactory and feeding preferences of $H$. axyridis are likely explained by the interaction between grape sugar content, presence of split skins and limited or absence of excessive microbial contamination. Although previous studies have shown a correlation between the presence of $H$. axyridis and grape damage, our results suggest that this relationship is more complex; grape damage is necessary for feeding by $H$. axyridis, but physical damage results in further berry degradation due to fungal and bacterial infection, which may not be attractive to the beetles. Future work needs to examine response of $H$. axyridis to specific grape-produced volatiles, mixes of volatiles, and to different cultivars, as well as determine the threshold of attractiveness/repellency of chemicals associated with spoilage. These preliminary data provide direction for the design of an integrated and environmentally sustainable push-pull strategy for managing this important vineyard pest. 


\section{Acknowledgements}

The authors would like to acknowledge the field support of Cara McCreary, Indrajith Wickramananda, and Ryan Brewster, and are grateful to Vincor Canada for donating vineyard space and grapes for this project. We would like to acknowledge the laboratory support of Kristen Eddington and the helpful suggestions of Neil Carter at the onset of this study. We would also like to thank the landowners and vintners of Niagara, Ontario. The following individuals are sincerely thanked for their invaluable contributions: Lisa Dowling, Christine Bahlai, Dr Ai-Lin Beh, Dr Mark Sears, Dr Helen Fisher, Jamie-Lee Robb, and Kerrie Pickering. This research was funded by an Ontario Grape and Wine Research Inc grant to RHH, DI and GJP, an Ontario Ministry of Agriculture, Food and Rural Affairs - University of Guelph Sustainable Production Program grant to RHH, a Natural Sciences and Engineering Research Council of Canada Strategic Project Grant to GJP and DI, and by the Wine Council of Ontario and Grape Growers of Ontario.

\section{References}

[1] Koch, R.L., Burkness, E.C., Wold Burkness, S.J. \& Hutchison, W.D., Phytophagous preferences of the multicolored Asian lady beetle (Coleoptera: Coccinellidae) for autumn-ripening fruit. Journal of Economic Entomology, 97, pp. 539-544, 2004.

[2] Pickering, G.J., Lin, J., Riesen, R., Reynolds, A., Brindle, I. \& Soleas, G., Influence of Harmonia axyridis on the sensory properties of white and red wine. American Journal of Enology and Viticulture, 55, pp. 153-159, 2004.

[3] Pickering, G.J., Lin, J., Reynolds, A., Soleas, G., Riesen, R. \& Brindle, I., The influence of Harmonia axyridis on wine composition and aging. Journal of Food Science, 70, pp. 128-135, 2005.

[4] Botezatu, A. \& Pickering, G.J. Ladybug (Coccinellidae) taint in wine. Understanding and Managing Wine Quality and Safety, ed. A.G. Reynolds, Woodhead Publishing Limited: Cambridge, U.K., pp 418-429.

[5] Pickering, G.J., Lin, J., Reynolds, A., Soleas, G. \& Riesen, R., The evaluation of remedial treatments for the wine affected by Harmonia axyridis. International Journal of Food Science \& Technology, 41, pp. 7786, 2006.

[6] Ontario Ministry of Agriculture, Food and Rural Affairs (OMAFRA), Fruit Production Recommendations 2008-2009 (Publication 360). Queen's Printer for Ontario: Toronto, 2008.

[7] Seko, T., Yamashita, K., \& Miura, K., Residence period of a flightless strain of the ladybird beetle Harmonia axyridis Pallas (Coleoptera: Coccinellidae) in open fields. Biological Control, 47, pp. 194-198, 2008.

[8] Ker, K.W. \& Pickering, G.J., Biology and control of the novel grapevine pest - the multicolored Asian lady beetle Harmonia axyridis. Crops: Quality, Growth and Biotechnology, ed. R. Dris, WFL Publisher: Helsinki, pp. 991-997, 2005. 
[9] Miller, J.R., Cowles, R.S., Stimulo-deterrent diversion: a concept and its possible application to onion maggot control. Journal of Chemical Ecology, 16, pp. 3197-3212, 1990.

[10] Cook, S.M., Khan, Z.R. \& Pickett, J.A., The use of push-pull strategies in integrated pest management. Annual Review of Entomology, 52, pp. 375400, 2007.

[11] Galvan, T.L., Koch, R.L. \& Hutchison, W.D., Impact of fruit feeding on overwintering survival of the multicolored Asian lady beetle, and the ability of this insect and paper wasps to injure wine grape berries. Entomologia Experimentalis et Applicata, 128, pp. 429-436, 2008.

[12] Galvan, T.L., Burkness, E.C. \& Hutchison W.D., Influence of berry injury on infestations of the multicolored Asian lady beetle in wine grapes. Plant Health Progress, doi:10.1094/PHP-2006-0607-01-BR, 2006.

[13] Bahlai, C.A., Welsman, J.A., Macleod, E.C., Schaafsma, A.W., Hallett, R.H. \& Sears, M.K., Role of visual and olfactory cues from agricultural hedgerows in the orientation behaviour of multicoloured Asian lady beetle (Coleoptera: Coccinellidae). Environmental Entomology, 37, pp. 973-979, 2008.

[14] Ough, C.S. \& Were, L., Sulfur dioxide and sulphites. Antimicrobials in Food, 3rd ed., eds. P. M. Davidson, J. N. Sofos \& A. L. Branen, CRC Press: New York, pp. 143-167, 2005.

[15] Balasubramaniam, R. \& Poole, P., Botrytis control - PMS (potassium metabisulfite) - another weapon against Botrytis. Winepress, 37, pp. 10-11, 1995.

[16] Vet, L.E.M., Van Lenteren, J.C., Heymans, M. \& Meelis, E., An airflow olfactometer for measuring olfactory responses of hymenopterous parasitoids and other small insects. Physiological Entomology, 8, pp. 97106, 1983.

[17] McCornack, B.P., Koch, R.L., \& Ragsdale, D.W., A simple method for infield sex determination of the multicolored Asian lady beetle Harmonia axyridis. Journal of Insect Science, 7, pp. 1-12, 2007.

[18] Bartlett, M.S., The use of transformations. Biometrics, 3, pp. 39-52, 1947.

[19] Sokal, R.R., \& Rohlf, F.J. 1995. Biometry. W.H. Freeman and Company, New York.

[20] Nurgel, C., Pickering, G.J. \& Inglis, D.L., Sensory and chemical characteristics of Canadian ice wines. Journal of the Science of Food and Agriculture, 84, pp. 1675-1684, 2004.

[21] Pettersson, J., Birkett, M.A. \& Pickett, J.A., Pyrazines as attractants for insects of order Coleoptera. International Publication Number WO 99/37152, 1999.

[22] Taper, M.L. \& Lele, S.R. The Nature of Scientific Evidence: Statistical, Philosophical and Empirical Considerations. University of Chicago Press: Chicago, 2004.

[23] Glemser, E.J., Dowling, L., Hallett, R.H., Inglis, D., Pickering, G.J., McFadden-Smith, W.H. \& Sears, M.K., A novel method for controlling 
Harmonia axyridis (Coleoptera:Coccinellidae) in vineyards. Environmental Entomology (In review), 2011.

[24] Glemser, E.J., Bahlai, C.A., Brewster, R., Beh, A.L., Ker, K., Inglis, D., Pickering, G., Hallett, R.H. \& Sears, M.K. Orientation of Harmonia axyridis (Coleoptera: Coccinellidae) to volatiles associated with ripe or damaged wine grapes. Vitis vinifera (In preparation), 2011.

[25] Pickering, G.J., Ker, K. \& Soleas, G.J., Determination of the critical stages of processing and tolerance limits for Harmonia axyridis for 'ladybug taint' in wine. Vitis, 46, 85-90, 2007.

[26] Penkett, S.A., Jones, B.M.R., Brice, K.A. \& Eggleton, A.E.J., The importance of atmospheric ozone and hydrogen peroxide in oxidising sulphur dioxide in cloud and rainwater. Atmospheric Environment, 41, pp. 154-168, 2007.

[27] Galvan, T.L., Burkness, E.C. \& Hutchison, W.D., Enumerative and binomial sequential sampling plans for the multicolored Asian lady beetle (Coleoptera: Coccinellidae) in wine grapes. Journal of Economic Entomology, 100, pp.1000-1010, 2007.

[28] Smilanick, J.M., Ehler, L.E. \& Birch, M.C., Attraction of Carpophilus spp. (Coleoptera: Nitidulidae) to volatile compounds present in figs. Journal of Chemical Ecology, 4, pp. 701-707, 1978.

[29] Phelan, P.L. \& Lin, H., Chemical characterization of fruit and fungal volatiles attractive to dried-fruit beetle, Carpophilus hemipterus (L.) (Coleoptera: Nitidulidae). Journal of Chemical Ecology, 17, pp. 1253-1272, 1991.

[30] Domek, J.M. \& Johnson, D.T., Inhibition of aggregation behavior in the green June beetle. Environmental Entomology, 19, pp. 995-1000, 1990.

[31] Hammons, D.L., Kurtural, S.K. \& Potter, D.A., Japanese beetles facilitate feeding by green June beetles (Coleoptera: Scarabaeidae) on ripening grapes. Environmental Entomology, 37, pp. 608-614, 2008.

[32] Hammons, D.L., Kurtural, S.K., Newman, M.C. \& Potter, D.A., Invasive Japanese beetles facilitate aggregation and injury by a native scarab pest of ripening fruits. Proceedings of the National Academy of Sciences, 106, pp. 3686-3691, 2009.

[33] Al Abassi, S., Birkett, M., Petterson, J. \& Pickett, J., Ladybird beetle odour identified and found to be responsible for attraction between adults. Cellular and Molecular Life Sciences, 54, pp. 876-879, 1998. 